\title{
Reorganization and IT Implementation in Campus Management: The Project "PuL" at RWTH Aachen University
}

\author{
Marcel Lämmerhirt ${ }^{1}$, Marguerite Franssen ${ }^{2}$, and Christoph Becker ${ }^{1}$ \\ ${ }^{1}$ Centre for Computing and Communication, RWTH Aachen University, Germany \\ \{laemmerhirt, c. becker\} arz.rwth-aachen. de \\ ${ }^{2}$ Department of Academic Affairs and Registrar's Office, RWTH Aachen University, Germany \\ marguerite. franssen@zhv.rwth-aachen. de
}

\begin{abstract}
Managing tasks accruing in the context of the student life cycle in higher education requires effective and transparent organizational processes as well as a powerful information technology (IT) support. Both aspects are the fundamental components of a university-wide project named "PuL" at RWTH Aachen University. Primarily, the project aims at describing optimized processes in examination and teaching management. In this context, elaborated methods of Business Process Modeling (BPM) are used to create comprehensible and realizable process descriptions. These organizational target processes form the basis for the second objective of the project: the introduction of an integrated supporting IT system (Campus Management System). The final process descriptions supply IT system requirements which are edited in a comprehensive catalogue of requirements. The project stages following this aim to find an appropriate software provider in a tendering procedure and to introduce subsequently the IT system into the organization. This paper will expose the main findings of the project "PuL" at RWTH Aachen University and will illustrate the key aspects for a successful project realization. Focal points are the business process modeling and the requirements analysis which are indispensable for the success of introducing new organizational processes and a new Campus Management System.
\end{abstract}

Keywords: Campus Management System, student lifecycle, reorganization in higher education, process management, business process modeling.

\section{Introduction: The Bologna Process and Campus Management}

The efficient and effective fulfillment of tasks accruing in the context of the student life cycle of a university puts high requirements on procedures, services and structures. Students need a broad and full range of services beginning at registration for and attendance of courses, and ending at the completion of examinations at the later alumni status. Rising levels of competition between universities for suitable students especially steps up pressure in favor of excellent general conditions in the field of teaching [1]. 
Considering the German landscape of higher education, it is evident that many universities pursue goals to optimize their offerings and structures in this field. In this regard, it is useful to distinguish between (1) the organizational processes and (2) the capabilities of a supporting information technology system (IT system).

(1) Due to the Bologna process and decentralized organizational structures constituted by autonomous units, increasing complexity in study administration complicates optimal planning, implementation and control of processes in the field of teaching in higher education. On the one hand the introduction of the guidelines within the Bologna process implies more standardization, monitoring and in effect more administrative efforts. On the other hand the conflicting area of tension between the central university administration (the university directorate) and the faculties slows down and hinders decisions and harmonization. This is associated with increased organizational requirements that must be borne by all participants from the central university administration, the faculties and teaching staff as well as students. As an example, the sevenfold increase of examinations that need to be performed is a case in point. Therefore, it is a necessary main objective to uncover and to remedy inefficiencies, ineffectiveness and lack of transparency in the organizational processes at a university.

(2) Because of the quantitative and qualitative complexity of these organizational processes in a large university, supporting IT systems are indispensable. Without support tools, mass actions could not to be mastered, e.g. the registration for courses and examinations, the submission of marks or data management. But the existing heterogeneous system landscape as well as isolated IT applications and shadow systems create inefficiencies, lead to a lack of transparency and coordination, and could thwart the university-wide processes. In this regard, it is a main objective to introduce an integrated system supporting the organizational processes of the whole university. However, limited financial resources require an accurate estimation about which procedures and functions have to be supported by an integrated IT system. Therefore, the definition and weighting of functional and nonfunctional requirements of a campus-wide supporting IT system is an important process and must be adapted to defined organizational processes.

To meet these challenges, RWTH Aachen University in Germany started a project in order to reorganize processes and to introduce a new IT system. The following sections will present the project, which deals with the aforementioned issues in the context of a single university.

\section{The Project "PuL": Reorganization and IT Support in Campus Management}

Based on the scenario introduced in the preceding section, in 2010, RWTH Aachen University initialized a single university project "Prüfungsleistungs- und Lehrveranstaltungsmanagement (PuL)". The RWTH Aachen University is one the biggest German universities and belongs to leading institutes of technology in Europe. In 2011, more than 35,000 students were registered in 126 courses of studies in 9 faculties. Nearly 5,000 of them were international students. At RWTH Aachen 
University about 500 professors teach and do research supported by more than 4,000 scientific employees and more than 2,000 non-scientific employees.

The first objective of the project aims to run an actual analysis to check and reveal the structures, procedures and decision criteria in the three main working fields of the project. These fields refer to the modeling of courses of studies, the planning of courses, and the managing of examinations.

The second objective is to create realizable, sustainable and transparent organizational target processes using existing resources at the University. This aspect includes also the main critical needs of the project: (a) a coordinated discussion within the University about the question on how the processes should be modeled; (b) a specification of the communication and implementation of the target processes; and (c) concepts and methods to measure how the processes will reach the objectives of feasibility, sustainability and transparency.

Finally, the findings from the target processes will determine the implementation of an efficient integrated software solution that will support the execution of the modeled processes.
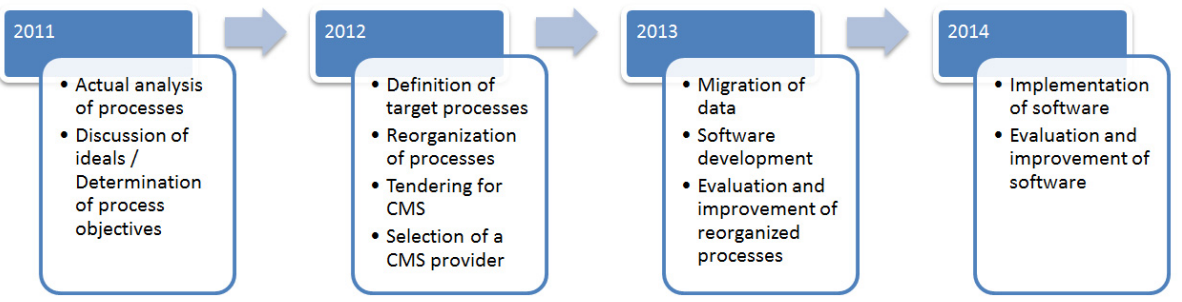

Fig. 1. Planned course of the project "PuL" at RWTH Aachen University (Source: own creation 2012)

Based on these objectives, the project consists of two main working packages: a reorganization using target processes; and the implementation of a new supporting IT system. The approaches and results of these two working packages will structure the project execution as well as the following elements (see Figure 1).

\section{Actual Analysis and the Definition of Target Processes}

Reorganization aims at the definition, improvement and harmonization of organizational processes. It is an objective to clarify responsibilities for tasks and procedures, to reach more transparency and quality of service and to improve the communication channels. In this respect, the analysis and the modeling of business processes was a main work package of the project [2].

Business processes describe a coherent and completed sequence of activities that are performed step by step and are necessary for the execution of an operational task. While the business process analysis includes the investigation of structural strengths and weaknesses in actual organizational business processes, the modeling forms optimized target processes [2]. For example, in the field of course planning, the analysis reveals the problem of planning without any course overlap and the inefficient distribution of room resources. Representatives of faculties and teaching 
staff, the central administration, the Centre for Computing and Communication, as well as students, participated in working groups to create target processes modeled in Business Process Modeling Notation (BPMN) language. The following figure gives a summary of the main business processes (see Figure 2 "Process Map").

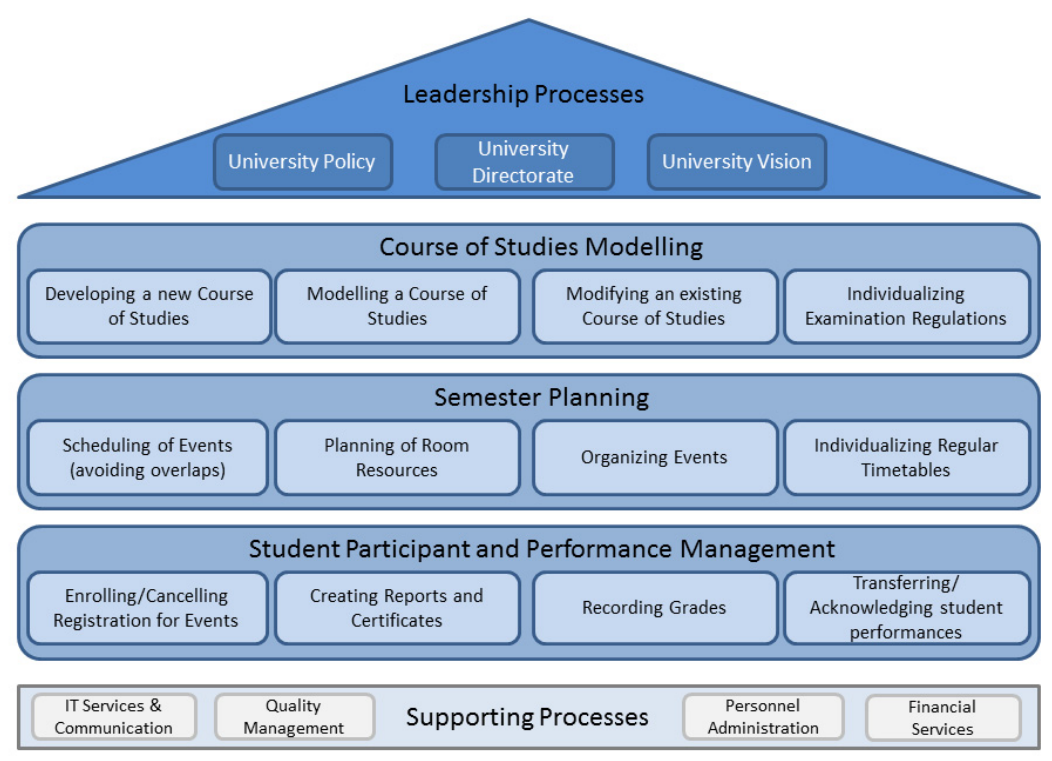

Fig. 2. Process map for examination and teaching management at RWTH Aachen University (Source: own creation 2012)

On the top layer, the leadership or management processes of the university provide a framework for the core processes in the middle of the map. Typical management processes include "Corporate Governance" and "Strategic Management". The base level contains the supporting processes, for example IT services and communication or personnel administration, which are used in all core processes. The operational processes in the middle constitute the core business, and create the so-called "primary value stream": course of study modeling, semester planning as well as student participation and examination management.

The defined target processes are the basis for the reorganization procedure as well as for the implementation of a new supporting IT system. The following section presents the first project activities for the introduction of this new system.

\section{The Introduction of a New Campus Management System}

A Campus Management System (CMS) comprises all functionalities for managing the student life cycle. A CMS can be defined as an integrated application system offering a single point of data entry and user interface, accessible information in real-time and support for procedures and functions across the board. Additionally, CMSs are 
implemented as customizable and modularized standard software and contain all functions for operational activities and business intelligence [3].

The important challenges for introducing a CMS can be summarized by the terms "decontextualization" and "recontextualization". While decontextualization describes the translation from human activities and organizational practices into algorithms and software code, recontextualization considers a second "translation" from formalized activities into the real context of use:

"The notion of decontextualization versus recontextualization emphasizes that the challenge of software development is not only writing correct code and providing ample functionality, but integrating new technology into its social and organizational context [...]." [4]

Specifically, procedures of recontextualization require high efforts because of the complex scenarios of use and high expectations of future users [5]. Furthermore, investigations show that weak organizational processes often shift the blame onto IT systems [4]. At RWTH Aachen University the existing IT services and systems make the conditions more difficult; since 2001 RWTH Aachen University operates different systems for managing lectures, courses and examinations which have been constantly developed and extended (e.g. a virtual examination office, and teaching assessment or integration of an e-learning platform based on Microsoft SharePoint). While in 2003 only a few thousand interactions were counted in the first lecture week, the demand grew to nearly 30 million interactions in 2010 [6]. This working IT service landscape increases the user expectation - an important aspect that has to be considered in the project "PuL". These expectations do not only refer to functional requirements but also to quality requirements such as load response, performance and security issues.

With regard to weak organizational processes shifting blame onto IT systems [4], it is essential to apply large efforts to the specification of need for fulfilling and satisfying requirements as well as the mastering of the main challenges - change management (substitution of existing systems and migration of databases) and process mapping (support of process workflows and role concepts).

All aspects mentioned above will be acquired by a Europe-wide tendering procedure. A well-prepared catalogue of requirements containing use cases and functional as well as non-functional requirements aims to find suitable software as well as a cooperative provider.

\section{Conclusion and Recommendations}

The project "PuL" at RWTH Aachen University aims at improvement and harmonization of processes in the field of teaching in higher education. In this regard, the project combines the issues of process reorganization and IT implementation.

The reorganization is based on a comprehensive business process analysis and modeling to develop suitable and realizable target processes. The target processes determine consistent operational procedures as well as communication channels and responsibilities between roles involved. Additionally, the target processes supply the crucial requirements for a tendering procedure, which is planned for a new supporting 
IT system. The successful development and implementation of this Campus Management System will be one of the main future challenges of the project.

First experiences show that it is decisive to invest in professional project management and project communication. Although coordination and communication within the University needs time and effort, it is absolutely necessary to get the critical mass involved. In this context, it is important to consider that there will be probably no minimization of resources. But consequently the reorganization reaches a higher level of transparency, an improved distribution of workload and therefore a higher degree of satisfaction of University staff. These benefits have to be communicated and spread within the University. However, it is very difficult to harmonize the processes. In a University as a loosely coupled expert system, it is necessary to find a balance between top-down decisions and bottom-up approaches.

Furthermore, the differentiation between process reorganization and the implementation of an IT system is important. The introduction of a Campus Management System without analyzing and reorganizing related processes in advance does not work. If the project includes no software independent concept for reorganization the project will face further problems. There will be a big deviation between the scope of system services and the expectations of the users. The missing concept will lead to a missing of the precise definition of objectives and of the project scope. And it will be possible to underestimate the degree of complexity of the project.

Future experiences should be published to give recommendations for other planned projects.

\section{References}

1. Hilbert, A., Schönbrunn, K., Schmode, S.: Student relationship management in Germany foundations and opportunities. Management Revue 18(2), 204-219 (2007)

2. Becker, J.: Was ist Geschäftsprozessmanagement und was bedeutet prozessorientierte Hochschule? In: Klapper, F., Degkwitz, A. (eds.) Prozessorientierte Hochschule. Allgemeine Aspekte und Praxisbeispiele. Bock und Herchen, Bad Honnef, pp. 8-22 (2011)

3. Alt, R., Auth, G.: Campus Management System. Business \& Information Systems Engineering 3, 187-190 (2010)

4. Janneck, M.: Challenges of Software. Recontextualization: Lessons Learned. In: CHI 2010, Atlanta, GA, April 10-15, pp. 4613-4627 (2010)

5. Sprenger, J., Klages, M., Breitner, M.H.: Cost-Benefit Analysis for the Selection, Migration, and Operation of a Campus Management System. Business \& Information Systems Engineering 4, 219-231 (2010)

6. Gebhardt, M.: 10 years Campus Management at RWTH Aachen University - an interim report. Autumn meeting of ZKI in 2011 (2011), accessible at

http://timms.uni-tuebingen.de/List/List01.aspx?rpattern= UT_20110913_006_zki_0001 